\title{
Cultura escolar evangélica: implicações sobre os sentidos das práticas corporais
}

\section{Evangelical school culture: implications on the meanings of body practices}

\section{Cultura escolar evangélica: implicaciones en el significado de las prácticas corporales}

\author{
iD (9) Márcia Cristina Rodrigues da Silva Coffani \\ Universidade Federal de Mato Grosso, Cuiabá, Mato Grosso, Brasil \\ e-mail: marciacoffani@hotmail.com \\ (iD) Cleomar Ferreira Gomes \\ Universidade Federal de Mato Grosso, Cuiabá, Mato Grosso, Brasil \\ e-mail: gomescleo.cg@gmail.com
}

Resumo: Este trabalho investigou as relações e tensões do processo de educação do corpo de jovens, alunos do Ensino Médio, presentes no cotidiano de uma escola evangélica assembleiana em Cuiabá-MT, buscando uma reflexão sobre os sentidos das práticas corporais nas aulas de Educação Física. A pesquisa é qualitativa, etnográfico-descritiva e foram analisadas fontes documentais; observações do cotidiano escolar e das aulas de Educação Física; entrevistas com os jovens alunos do Ensino Médio. Sinaliza-se a importância da compreensão de que, para a cultura escolar de instituições educativas evangélicas tradicionais, a aula de Educação Física e as práticas corporais são historicamente objetos de interdição e tensão em relação aos ensinamentos religiosos evangélicos imbricados à questão de gênero.

Palavras - chave: Cultura Escolar Evangélica. Educação do Corpo. Práticas Corporais.

Abstract: This work investigated the relationships and tensions in the
education process of the body of young high school students present in 
the daily life of an evangelical assembly school in Cuiabá-MT to reflect on the meanings of bodily practices in Physical Education classes. The research is qualitative, ethnographic-descriptive, documentary sources were analyzed; observations of school routine and Physical Education classes; interviews with young high school students. The importance of understanding that for the school culture of traditional evangelical educational institutions, the Physical Education class and body practices are historically the object of interdiction and tension in relation to evangelical religious teachings imbricated to the gender issue is highlighted.

Keywords: Evangelical School Culture. Body Education. Body Practices.

Resumen: Este trabajo investigó las relaciones y tensiones en el proceso educativo del cuerpo de jóvenes estudiantes de secundaria presentes en la vida cotidiana de una escuela asamblea evangélica en Cuiabá-MT para reflexionar sobre los significados de las prácticas corporales en las clases de Educación Física. La investigación es cualitativa, etnográficodescriptiva, se analizaron fuentes documentales; observaciones de la rutina escolar y las clases de educación física; entrevistas con jóvenes estudiantes de secundaria. Se destaca la importancia de comprender que para la cultura escolar de las instituciones educativas evangélicas tradicionales, las prácticas de clase y corporal de Educación Física son históricamente objeto de interdicción y tensión en relación a las enseñanzas religiosas evangélicas imbricadas a la cuestión de género.

Palabras clave: Cultura evangélica escolar. Educación del cuerpo. Prácticas Corporales.

Submetido em: 25-09-2019

Aceito em: 28-01-2021 


\section{Introdução}

Este trabalho investigou as relações e tensões sobre a educação do corpo de jovens, alunos do Ensino Médio (EM), presentes no cotidiano de uma escola evangélica assembleiana (EEA) em Cuiabá - MT, buscando uma reflexão sobre os sentidos das práticas corporais nas aulas de Educação Física (EF).

\section{Métodos}

A pesquisa foi qualitativa, de tendência etnográfico-descritiva, pois retratou tensões, concessões e restrições relacionadas ao processo de educação do corpo do jovem aluno com implicações nas práticas corporais permitidas e vivenciadas nas aulas de EF no EM.

Envolveu a análise de fontes documentais, como o Projeto Pedagógico da EEA e demais projetos educativos; observações do contexto escolar e das aulas de EF descritas em diário de campo; e entrevistas semiestruturadas com 10 jovens alunos do EM.

As incursões in loco ocorreram no período letivo de 2016, às quartas-feiras e sextas-feiras, das 7 às 12h30, para apreensão do cotidiano escolar e das aulas de EF. Observou-se os ritos de acoIhida dos jovens alunos, o momento do recreio, os eventos de socialidade juvenil; as aulas de EF nas turmas do EM (primeiro A e B, segundo A e terceiro A); e a realização das Olimpíadas Escolares.

O processo de análise da pesquisa integrou "o olhar, o ouvir e o escrever" (OLIVEIRA, 2000), ao apreender os fenômenos sociais, contextualizando-os em sua trivialidade do cotidiano, inscrevendo-os numa proposição de foro narrativo dialógico, ao empregar a "triangulação" de dados em perspectiva socioantropológica. 
Cultura escolar evangélica: implicações sobre os sentidos das práticas corporais Márcia Cristina Rodrigues da Silva Coffani • Cleomar Ferreira Gomes

\section{Resultados}

\section{Práticas educativas no cotidiano da EEA}

A EEA é uma instituição educativa particular, gerida como obra social pela Igreja Evangélica Assembleia de Deus, que funciona no prédio do templo central de evangelismo pentecostal em CuiabáMT. Preocupa-se com a formação educacional, moral e religiosa dos alunos que atende em todas as etapas da Educação Básica, segundo os preceitos evangélicos assembleianos do pentecostalismo tradicional.

Com uma localização geográfica privilegiada no epicentro governamental e político da cidade, a escola estabelece fronteiras simbólicas e físicas com estabelecimentos públicos e comerciais diversos, como Shopping Center, lojas de redes de fast food, entre outros. Não se trata de uma escola de bairro, que atende a um público específico, há, em seu espaço cotidiano, alunos com condições sociais, culturais, econômicas e até mesmo religiosas apenas aparentemente homogêneas.

Inicialmente, suspeitou-se que a intenção subjacente à criação da EEA fosse de assegurar a propagação e perpetuidade do código religioso evangélico, ao publicá-lo aos filhos dos membros da Igreja. Assim, ao mesmo tempo em que se ensina, se inscreve e se consagra a doutrina religiosa que, conforme os estudos weberianos, é influenciada por princípios do ascetismo laico, rejeição à mundanidade e proibição da idolatria pela materialidade (WEBER, 2001). Contudo, a pesquisa identificou que a proposta educativa da EEA é externada aos filhos das demais famílias, se assim o desejarem, independentemente da sua filiação religiosa. Apesar de ter a maioria de alunos oriundos de famílias evangélicas, a EEA tem enfrentado inúmeros desafios porque no seu todo social se revelam individualidades, tomadas como o "lugar" em que atua uma pluralidade de determinações relacionais, portanto, sociais (CERTEAU, 2009). 
Cultura escolar evangélica: implicações sobre os sentidos das práticas corporais Márcia Cristina Rodrigues da Silva Coffani • Cleomar Ferreira Gomes

A EEA investe em práticas educativas para formação do devoto ao ensinar e formatar os modelos de apresentação individual e coletiva do corpo aos jovens alunos, influenciando as imediações da vida social, a expressão da corporeidade e, por conseguinte, o sentido das suas práticas corporais. Ali se consagra uma orientação disciplinar educativa, de fundo religioso evangélico tradicional, que prima pela conservação do corpo (PPP EEA 2013) e que tolera duas aulas semanais de EF para o EM, no turno escolar, porém sem dispor de espaço físico adequado e marcadas pela interdição da bola e dos esportes.

O "reencontro com Deus", proposto no Projeto Pedagógico da EEA (2013), foi notado com a observação da prática do "Devocional" coletivo, diariamente realizado, em cada turma, da exposição de cartazes de orientação religiosa evangélica, da adoção de um conjunto de regras de apresentação do corpo, que parecem se inspirar nos princípios do ascetismo do protestantismo (WEBER, 2001). Essas são estratégias educativas da EEA que indicam a vontade subjacente que preside a totalidade das suas atividades pedagógicas, que é preencher a vida dos jovens alunos com mensagens fundamentalmente religiosas, prenhes de exemplos, que realçam "[...] a insuperável insuficiência e fraqueza dos poderes humanos" (BAUMAN, 1998, p. 212), o que justifica a devoção religiosa cristã evangélica.

Na EEA não há um espaço que se configure num pátio de convivência escolar onde os jovens alunos possam socializar suas angústias, dúvidas e previsões de vida, entre seus pares, e em situações livres das obrigações escolares como o horário de recreio. 0 que não aproxima as relações dos jovens alunos com a escola ou entre si no espaço/tempo escolar.

A falta de um espaço para ser chamado de "nosso" e a dificuldade do estabelecimento de um tempo de intimidade entre os alunos durante o recreio, inibem a formação de "teias" de relações e contatos corporais entre os jovens, que não lhes permitem compartilhar suas experiências juvenis ligadas à socialidade, à religiosidade, à experiência amorosa e sexual, aos projetos de futuro, ao 
Cultura escolar evangélica: implicações sobre os sentidos das práticas corporais Márcia Cristina Rodrigues da Silva Coffani • Cleomar Ferreira Gomes

desempenho escolar, entre outras. Falta-lhes um lugar que permita que eles possam vivenciar a afetividade e proximidade com seus pares, elementos fundantes da constituição social, ao mesmo tempo em que confirmaria os laços próximos e lhes permitiria resistir às tentativas de uniformização (MAFFESOLI, 1987).

Mesmo durante o recreio persiste uma moralidade religiosa tradicionalista que parece inibir práticas afetivas de contato corporal entre os jovens alunos, atuando como um fator potencial para valorização de determinadas representações sobre sexualidade, corpo e juventude. Assim, compreendeu-se que a educação dos corpos evangélicos é estética e moral. Como o uso da bola não é permitido nem para as aulas de EF, a EEA não dispõe de uma mesa de ping-pong ou outra forma de jogo com bolas que possa ser usufruída pelos alunos, e nem mesmo se ouve o som da Estação de Rádio que ali funciona.

Os jovens alunos parecem ser acomodados à vida cotidiana "dentro" da escola, institucionalizada de acordo com as práticas religiosas evangélicas conservadoras dos "usos do corpo" (MAUSS, 2003). A "fabricação do corpo evangélico" assume uma noção de natureza social do "habitus" que, na compreensão de Mauss (2003), se aprende sancionada pela tradição.

A pesquisa registrou que o cotidiano da EEA é "animado" por um processo de educação do corpo marcado por idiossincrasias sociais, de fundo moral e religioso, que não pode ser compreendido como "[...] simplesmente um produto de não sei que arranjos e mecanismos puramente individuais, quase inteiramente psíquicos" (MAUSS, 2003, p. 404). Mas, repleto de intermediações anatômicas e sociológicas que, para serem compreendidas, carecem de um tríplice ponto de vista (sociológico, psicológico e fisiológico), o do "homem total" (MAUSS, 2003), visto que os gestos mais naturais são fabricados por normas coletivas (VIGARELLO, 2008).

O regramento do corpo apreendido por esses jovens na convivência familiar, na Igreja e na EEA se expressa na "fabricação" do seu modo de ser jovem, perceptível na gestualidade/corporeidade 
Cultura escolar evangélica: implicações sobre os sentidos das práticas corporais Márcia Cristina Rodrigues da Silva Coffani • Cleomar Ferreira Gomes

contida de seus corpos, o que compõe a organização de um código público de conduta permitido ao evangélico, ou seja, de um sistema de cultura evangélico construído e (in)corporado socialmente, principalmente pelas jovens alunas. Há mesmo uma "fabricação do eu, da pessoa" que é coletiva e submetida aos desígnios religiosos (MAUSS, 2003, p. 392). A autovigilância, o autocontrole e o autodisciplinamento do corpo são elementos tensionadores da condição juvenil do evangélico, seja dentro ou fora da EEA.

Não foram registados dentro da EEA o uso pelos alunos de acessórios (correntes e pulseiras de metal, piercings, brincos, bonés, tênis coloridos, entre outros) ou estilos (cabelos coloridos ou extravagantes, com cortes não convencionais) que demarcassem a sua identificação com as culturas juvenis, aceitas como expressões do "estar-junto" (MAFFESOLI, 2011).

O que está em evidência é a "tribo evangélica", com a (in)corporação acumulativa de saberes e modos corporais que denotam um estilo próprio de ser evangélico, que se orienta pela conservação do corpo, exemplificado pelo majoritário uso da saia pelas meninas e professoras, e da calça pelos meninos e professores, inclusive nas aulas de EF. A obrigatoriedade do uso da saia e da calça (demarcando os sexos) se trata de um padrão cultural que modela, disciplina e salvaguarda o comportamento público do corpo do evangélico.

Apesar dos esforços que se mobilizam em torno da educação do corpo evangélico, as observações do/no/sobre o cotidiano da EEA revelaram incertezas sobre o alcance dessas práticas educativas, em querer "pôr a salvo o jovem evangélico", em suspensão das relações com as "coisas do mundo". Isso implica numa série de negociações entre o "permitido" e o "interdito", o "sagrado" e o "profano", que tem a intenção de moralização do corpo e da aprendizagem de uma gestualidade tipicamente religiosa, que não é natural, mas apreendida (RIGONI, 2009). Há que se registrar o uso difundido do celular entre os jovens alunos evangélicos para acessarem as redes sociais e a internet, bem como o movimento de colonização do espaço virtual pela ampla "cibervangelização". 
Cultura escolar evangélica: implicações sobre os sentidos das práticas corporais Márcia Cristina Rodrigues da Silva Coffani • Cleomar Ferreira Gomes

A EEA estabelece laços de reciprocidade com os jovens alunos e suas famílias, tendo em pauta sua missão educacional evangélica, a partir de estratégias pedagógicas como a figura do "Professor Conselheiro de Sala", que orienta uma turma de ensino atuando na resolução de problemas de grupo relacionados às normas disciplinares, e ao professar da fé, principalmente em relação aos alunos não evangélicos.

A EEA desenvolve ações pedagógicas centradas na vivência das socialidades da juventude evangélica, como o festival de música. O gênero gospel é valorizado entre os alunos evangélicos. Para dar "vazão" ao viver de sua condição juvenil e, ao mesmo tempo, respeitar a condição religiosa, criou-se essa dinâmica pedagógica que permite aos jovens alunos evangélicos estabelecerem formas de socialidades entre si, nas quais o imperativo é o cooperar e celebrar os valores morais e religiosos. No evento, é autorizado ao corpo jovem "mostrar-se", mostrar o seu dom, desde que seja, "em nome e elevação do sagrado".

Há também o envolvimento dos jovens alunos em ações solidárias, como gincanas com a arrecadação de alimentos para doação às famílias carentes, o que ratifica o compromisso moral, religioso e de cidadania expresso no Projeto Pedagógico (2013) da EEA. Seu encerramento ocorre nas "Olimpíadas Escolares", que se revelaram como o principal evento de socialidade da juventude evangélica organizado pelos professores de EF da EEA.

Criou-se uma "brecha" no tempo/espaço pedagógico e curricular com a realização das "Olimpíadas Escolares" que possibilita "suprir" ou "driblar" a interdição da bola e dos esportes na EEA. O evento realizado anualmente num ginásio esportivo, fora do ambiente escolar, se caracteriza pelo participar cooperativo com a amenização da competitividade. Integra a cultura escolar, com a formação de equipes mistas, por cores, das quais participam alunos e professores. As provas realizadas são as mesmas atividades de ensino desenvolvidas nas aulas de EF, como "Rouba Bandeira", "Leva e Traz", "4 por 100", "Corridas", entre outras. Como o evento 
Cultura escolar evangélica: implicações sobre os sentidos das práticas corporais Márcia Cristina Rodrigues da Silva Coffani • Cleomar Ferreira Gomes

é feito num local alternativo, fora da escola, o segundo horário é destinado ao jogar, jogar bola, praticar esportes, recrear o corpo.

\section{O Jovem Aluno do EM da EEA}

Na EEA há uma maioria de alunos provenientes de famílias assembleianas que se dizem "criados no evangelho", entre eles fiIhos e/ou netos de pastores religiosos e autoridades da Igreja, o que referenda que a família é uma instituição credível que orienta a organização social dos jovens evangélicos.

Os questionamentos sobre: "O que seus pais acharam quando você veio estudar na EEA?"; “Você tem mais parentes diretos ou indiretos que estudaram na EEA?"; "Quem decidiu que você estudaria na EEA?"; "Por que você escolheu estudar na EEA?"; "Há quantos anos você estuda na EEA?"; "Você gosta da EEA?"; "O que você mais gosta na EEA?"; “Há algo que te incomoda na EEA?"; "Para que serve a escola?"; “O que espera ao terminar o EM?". As respostas dos jovens indicaram que a escolha pela escola evangélica é tensionada pela condição religiosa:

Na verdade, foi minha mãe que escolheu, né. Por aqui ser uma escola evangélica, porque meus pais são pastores. Então, ela né opinou para cá. (F. - Segundo A - F. - 17 anos).

Não foi bem uma escolha minha, né. Foi meus pais porque também são pastores. Meu irmão também estudou aqui, então... (C. Terceiro A - F. - 16 anos).

Há uma latente expectativa das famílias, que buscam educar seus filhos na EEA, por um ambiente escolar que professa o código religioso evangélico, de maneira que a escola e seus ensinamentos extrapolam as fronteiras do conhecimento científico para assumir a orientação religiosa. Isso inclui o agenciamento moral dos "usos 
Cultura escolar evangélica: implicações sobre os sentidos das práticas corporais Márcia Cristina Rodrigues da Silva Coffani • Cleomar Ferreira Gomes

permitidos do corpo" e fundamenta uma forma de educação de perspectiva sociológica geracional (PAIS, 1990) que espera a continuidade dos laços da fé.

Os jovens alunos esclareceram que a relação com a escola é baseada na valorização dos produtos escolares, um valor de troca e não um valor de uso. A escola é uma condição para desenvolvimento social e econômico, com vistas à obtenção de melhores condições financeiras e profissionais na vida adulta:

Bom, para mim ela serve como base prá preparamento, para faculdade, prá em outros casos também, é seja, concurso público, ou trabalho, cursos, qualquer coisa. (M. - Segundo A - M. - 16 anos).

As representações dos jovens alunos sobre as serventias da escola revelam que se trata de uma relação do devir, pautada em uma compreensão utilitarista da escola. Há uma vacância de sentidos sobre as condições, implicadores e funções sociais da escola na contemporaneidade que não podem ser creditadas como, unicamente, a preparação para o acesso ao Ensino Superior ou ao mundo do trabalho.

Apesar da identificação dos alunos com a EEA, foram desveladas situações de resistência e conflitos em relação ao ensino escolar marcado pela vigilante conservação dos "usos do corpo" (MAUSS, 2003), que invade a vida social dos jovens. Há uma vontade de "querer-existir" que releva uma problemática política entre o modelo cultural da escola, o postulado evangélico e a condição juvenil do jovem aluno do EM. O que demanda a experiência de outras formas culturais, ditas como plurais por Certeau (1995), de linguagem e expressão de dúvidas, ansiedades e interesses.

Identificou-se que em outras instituições educativas, que compartilham a orientação evangélica, há exceções, permissões e negociações sobre o corpo, quando os jovens alunos disseram que em outras escolas evangélicas tinham frequentado "a denominada prática da $\mathrm{EF}^{\prime \prime}$, inclusive com o ensino das modalidades esportivas com bola: 
Cultura escolar evangélica: implicações sobre os sentidos das práticas corporais Márcia Cristina Rodrigues da Silva Coffani • Cleomar Ferreira Gomes

Participava. É...tinha aula com bola. Eu acho que era menos puxado, era mais solto. Aqui o professor é mais disciplina, ele passa mais atividades com objetivos certos. (J. - Terceiro A - M. - 17 anos).

Participava, jogava bola, jogava vôlei. Tudo que referia bola, eu tava jogando. Sempre gostei de bola. De correr, de brincar, assim. Que nem brinca nas outras escolas. A gente sente falta. Ah! Era futebol. (F. - Segundo A - F. - 17 anos).

O pentecostalismo tradicional não é igual, pode ocorrer uma maior ou menor proximidade ao ascetismo protestante, entranhado ao modo de vida do evangélico, como sectarismo e rejeição às coisas mundanas e tolerância aos hábitos de uma sociedade globalizada com mudanças socioculturais entre os fiéis, por exemplo, como frequentar locais de diversão (praias, cinemas, teatros, estádios esportivos); assistir televisão; consumo de roupas, cosméticos e outros gêneros musicais; práticas de embelezamento do corpo e dos esportes.

As "vozes" dos jovens evangélicos sobre: "Quando você não está na escola, o que você faz, com quem, onde?" e "O que você faz no lazer? Nos finais de semana?", registraram que a sua vida social é marcada pela existência de tipos de lazer diferenciados dos outros jovens, que incluem os cultos religiosos e a participação das ações organizadas pela Igreja, como viagens para encontro de jovens, que "arrebanham os cordeiros", mantendo-os na consagração permanente da fé.

O lazer do jovem evangélico é vivido nos limites permitidos pelo itinerário religioso pentecostal. O que invade suas relações sociais com o mundo, exemplificados pelo gosto à leitura, à música gospel, à prática de instrumentos musicais utilizados nos cultos, o engajamento em ações com crianças na Igreja.

Diante do interdito dos "usos do corpo" (festas em boates e bailes noturnos, shows de artistas) e da desvalorização das práticas corporais, principalmente aquelas que possam profanar o 
Cultura escolar evangélica: implicações sobre os sentidos das práticas corporais Márcia Cristina Rodrigues da Silva Coffani • Cleomar Ferreira Gomes

corpo, como as técnicas de embelezamento, como o uso de maquiagens; de culto ao corpo, como as academias de ginástica e musculação e a prática de esportes de competição; entre outras. O corpo jovem evangélico parece assumir (in)conscientemente um conjunto de habitus (MAUSS, 2003) permitido pela condição religiosa, em concordância com o ethos religioso evangélico.

Os jovens alunos ilustram que mesmo nas situações de lazer e ócio, não há o deleite tolo ou entrega frívola do espírito aos prazeres do corpo. O pano de fundo é a reincidente oferta do imaginário social religioso evangélico, que toma o ócio como "pai de todos os vícios" (RUSSELL, 2002, p. 23), ou seja, que garante: "A ociosidade é má conselheira, tanto para as coletividades quanto para os indivíduos" (DURKHEIM, 2008, p. 28).

Os jovens alunos disseram optar por práticas sociais de lazer mais contemplativas do que as de risco e aventura, como caminhar no parque aos domingos, quando muito correr ou andar de bicicleta. Trata-se de um "exercício higiênico, simples e cotidiano" (VIGARELLO, 2008, p. 374). Essas práticas corporais parecem se "encaixar" na dimensão da tolerabilidade religiosa.

Os jovens evangélicos assumem uma condição juvenil mais diurna do que noturna, reflexo das suas convicções religiosas que condicionam as suas práticas sociais. O tempo noturno é utilizado para ir à Igreja exercer sua condição de devoto, para cuidar da sua orientação espiritual em "elevação do sagrado".

O corpo evangélico e suas práticas ordinárias de lazer (CERTEAU, 2012) tendem a resistir ao jogo de futebol, a habitar centros culturais de consumo globalizado e de expressão da cultura de massa, como Shoppings Center. Haja vista que essas práticas não representam a lógica social da qual fazem parte por aderência, cerceada e regulada pela sua condição religiosa evangélica, os jovens evangélicos partilham uma distinta visão e modo de vida próprio, que "[...] em princípios, guardam especificidades em relação àqueles compartilhados pelos/as demais jovens em sociedade" (ALVES, 2011, p. 83). 
Cultura escolar evangélica: implicações sobre os sentidos das práticas corporais Márcia Cristina Rodrigues da Silva Coffani • Cleomar Ferreira Gomes

Há um conjunto de interesses comuns entre os jovens alunos evangélicos, que lhes permite se identificarem como grupo, como a música Gospel, Instrumental e até mesmo Rock, Rap, desde que o conteúdo de suas letras não seja agressivo e imoral; tocar instrumento musical para os cultos religiosos; e a leitura, especialmente de conteúdo religioso.

Essas são práticas da vida cotidiana aceitas e compartilhadas pelo "modo de vida evangélico", que marcam as formas de socialidades juvenis. Não obstante, a vida desses jovens evangélicos é um território de colonização do sistema religioso evangélico, que exprime uma intenção de socialização da juventude de ordem funcionalista e tradicionalista.

\section{A dinâmica curricular e pedagógica da EF no EM da EEA}

Há um empenho pedagógico e curricular da EEA ao oferecer duas aulas semanais de EF, no turno escolar do EM. Este é, ou poderia vir a ser, um possível fator estimulador da participação dos jovens alunos das aulas de EF no EM, com potencial para redução das ausências ou rotatividade dos alunos às aulas.

As aulas de EF ocorreram sempre às sextas-feiras, concomitantemente, mas com as turmas separadas em meninos (com o professor de EF) e meninas (com a professora de EF), o que nos pareceu ser mais motivado pela orientação religiosa do que por uma ação pedagógica proposta pela EEA.

A EF na organização curricular do EM é proposta numa perspectiva humanizadora, ética e cidadã, sendo tarefa de cada disciplina viabilizar aproximações e diálogos "[...] com áreas do conhecimento, na busca da construção do pensamento plural e complexo" (PPP EEA, 2013, p. 450-451).

Adota como princípios orientativos do processo ensino-aprendizagem da disciplina: "[...] a concepção de corpo totalidade; o entendimento do corpo como produto e produtor de cultura; as práticas corporais como linguagem; a ludicidade como essência 
Cultura escolar evangélica: implicações sobre os sentidos das práticas corporais Márcia Cristina Rodrigues da Silva Coffani • Cleomar Ferreira Gomes

da qualidade de vida e da vivência plena da corporeidade [...]" (PPP EEA, 2013, p. 454, grifos nossos).

Constituem-se em objetivos gerais da EF, o desenvolvimento de competências como:

Apropriar-se da corporeidade por meio de diferentes práticas corporais;

Aprender criticamente as manifestações corporais produzidas pela humanidade;

Praticar movimentos corporais;

Promover a saúde voltada para a qualidade de vida;

Valorizar a ética, a estética e a política;

Conviver com a diferença e a diversidade;

Perceber a importância do empreendedorismo;

Valorizar o lazer, como prática de higiene e saúde física e mental (PPP EEA, 2013, p. 453).

Define-se como eixo da disciplina a Cultura Corporal de Movimento e os subeixos temáticos de conhecimentos: Jogos e Brincadeiras, Ginástica, Dança e Esporte (PPP EEA, 2013, p. 455, grifos nossos).

O Quadro 01 sintetiza a organização geral da proposta curricular de EF: 
Cultura escolar evangélica: implicações sobre os sentidos das práticas corporais Márcia Cristina Rodrigues da Silva Coffani • Cleomar Ferreira Gomes

Quadro 01 - Organização curricular da proposta de EF na EEA, em Cuiabá-MT.

\begin{tabular}{|c|c|c|}
\hline \multicolumn{3}{|c|}{ CULTURA CORPORAL DE MOVIMENTO } \\
\hline EDUCAÇÃO INFANTIL & ENSINO FUNDAMENTAL & ENSINO MÉDIO \\
\hline \multicolumn{3}{|c|}{ JOGOS E BRINCADEIRAS } \\
\hline Populares & \multirow{6}{*}{$\begin{array}{l}\text { Populares } \\
\text { De salão } \\
\text { Derivados dos esportes } \\
\text { Com raquetes } \\
\text { De outras culturas }\end{array}$} & Populares \\
\hline Simbólicos & & De salão \\
\hline Sensoriais & & Derivados dos esportes \\
\hline Brincadeira de roda & & Com raquetes \\
\hline Brinquedos industrializados & & Eletrônicos \\
\hline Construção de brinquedos & & Capoeira \\
\hline \multicolumn{3}{|c|}{ GINÁSTICA } \\
\hline Ginástica Historiada & $\begin{array}{l}\text { Geral } \\
\text { Artística } \\
\text { De acrobacias } \\
\text { Circuitos } \\
\text { Atividades circenses } \\
\text { Caminhada }\end{array}$ & $\begin{array}{l}\text { Hidroginástica } \\
\text { Alongamento Relaxamento } \\
\text { Caminhada } \\
\text { De academia }\end{array}$ \\
\hline \multicolumn{3}{|c|}{ ESPORTE } \\
\hline & $\begin{array}{l}\text { Atletismo } \\
\text { Basquetebol } \\
\text { Futsal } \\
\text { Handebol } \\
\text { Voleibol } \\
\text { Peteca } \\
\text { Natação }\end{array}$ & $\begin{array}{l}\text { Basquetebol } \\
\text { Futsal } \\
\text { Handebol } \\
\text { Voleibol } \\
\text { Peteca } \\
\text { Natação }\end{array}$ \\
\hline \multicolumn{3}{|c|}{ DANÇA } \\
\hline $\begin{array}{l}\text { Folclórica } \\
\text { Mímica } \\
\text { Dramatização } \\
\text { Teatro }\end{array}$ & $\begin{array}{ll}\text { Criativa } & \\
\text { Folclórica } & \\
\text { Nacional } & \\
\text { Internacional } & \\
\text { Movimentos } & \text { expressivos: } \\
\text { mímica, } & \text { pantomima, } \\
\text { dramatização } & \end{array}$ & $\begin{array}{l}\text { Criativa } \\
\text { Movimentos expressivos }\end{array}$ \\
\hline
\end{tabular}

Fonte: PPP EEA, 2013, p. 461.

As orientações metodológicas propõem que "[...] a Educação Física deve levar os alunos ao entendimento crítico das atividades propostas em aula, do lugar e do significado das práticas corporais na escola e na sociedade" (PPP EEA, 2013, p. 462).

Para o alcance dos objetivos e materialidade das orientações metodológicas, a EF pode utilizar diversos recursos didáticos, como apresentados na Proposta Pedagógica (PPP EEA, 2013, p. 463-464), como "ressignificação de tempos, espaços, regras e materiais utilizados no ensino da Educação Física; aulas expositivas 
Cultura escolar evangélica: implicações sobre os sentidos das práticas corporais Márcia Cristina Rodrigues da Silva Coffani • Cleomar Ferreira Gomes

ou dialogadas em círculos; uso de imagens e sons (filmes, vídeos, fotografias, desenhos, pinturas, propagandas, músicas, charges, murais, cordéis, documentários)".

Em relação à avaliação em EF, cita-se:

Ao ser considerada uma disciplina como as demais na instituição escolar, a Educação Física precisa também organizar estratégias de avaliação de seus conteúdos. Para isso, deve lançar mão das provas objetivas ressignificadas, da pesquisa, do debate, da análise de filmes e propagandas, da solução de problemas nas práticas corporais, entre outros (PPP EEA, 2013, p. 465).

A análise documental da proposta pedagógica para o ensino da EF surpreendeu pelo nível de elaboração teórica das ambições pedagógicas da disciplina, que sobrevive na EEA em meio a uma "nada sutil" redução de sua visibilidade em função do credo religioso, além das implicações e limitações pedagógicas sobre as "concretas" possibilidades de oferecimento das práticas corporais nas aulas.

A EF na EEA convive ainda com a proibição da prática com a bola, incidindo diretamente sobre os esportes que a utilizam, que são desaprovados por serem práticas corporais, possivelmente, geradoras de competitividade e ociosidade. Esse quadro é agravado pela falta de "espaço" e "tempo" pedagógicos adequados para as aulas de EF.

O planejamento anual da disciplina é elaborado pela professora de EF com formação acadêmica na área, conforme apresentado: 
Cultura escolar evangélica: implicações sobre os sentidos das práticas corporais Márcia Cristina Rodrigues da Silva Coffani • Cleomar Ferreira Gomes

Quadro 02 - Conteúdos das aulas de EF para o EM na EEA, em Cuiabá-MT.

\begin{tabular}{|c|c|}
\hline Conteúdos & Habilidades e Competências \\
\hline $\begin{array}{l}\frac{\text { Futsal }}{\text { jogo. }} \text { - Técnicas, táticas, regras e } \\
\text { Vôlei - Técnicas, táticas, regras e jogo. } \\
\text { Handebol }- \text { Técnicas, táticas, regras e } \\
\text { jogo. } \\
\text { Basquete - Técnicas, táticas, regras e } \\
\text { jogo. } \\
\frac{\text { Recreação }}{\text { queimadas, pegadores e estafetas. }} \\
\frac{\text { Peteca }- \text { Regras e jogo. }}{\text { Temas Transversais }}-\text { Obesidade, } \\
\text { ginástica de academia. }\end{array}$ & $\begin{array}{l}\text { Vivenciar o maior número de práticas corporais } \\
\text { possíveis. } \\
\text { Estabelecer relações individuais e sociais através do } \\
\text { movimento. } \\
\text { Aquisição de autonomia na criação, elaboração } \\
\text { e organização das práticas corporais, assumindo } \\
\text { uma postura crítica quando estiverem no papel de } \\
\text { espectadores das mesmas. } \\
\text { Criar a participação efetiva no mundo do trabalho em } \\
\text { relação à compreensão do papel do corpo no mundo da } \\
\text { produção no que se refere ao controle sobre o próprio } \\
\text { esforço, ao direito de repouso e ao lazer. } \\
\text { Relacionar a Educação Física com os temas transversais } \\
\text { saúde, ética, pluralidade cultural, trabalho, orientação } \\
\text { sexual e meio ambiente. } \\
\text { Oportunizar a aquisição, o aprimoramento e a } \\
\text { combinação de variadas formas de movimento. } \\
\text { Possibilitar aos alunos movimentar-se individual e } \\
\text { coletivamente, evitando discriminação em relação a si } \\
\text { próprio e ao grupo. }\end{array}$ \\
\hline
\end{tabular}

Nota: Construção da autora.

É importante registrar que no plano de ensino de EF para o EM não consta a forma de avaliação ou o procedimento metodológico da disciplina. Além disso, há uma centralidade em esportes com bola como conteúdo pedagógico das aulas de EF no EM. Contudo, as observações do cotidiano indicaram o silenciamento dessas práticas esportivas nas aulas.

Apesar da crítica feita à história da EF, a professora valoriza em seu planejamento de ensino o conteúdo esporte - melhor dizendo o "quarteto mágico" -, como se esse conteúdo fosse o principal e os demais (jogo e ginástica) meros coadjuvantes da prática pedagógica em EF na escola.

Essas são notas do fardo da relação simbiôntica da EF com o esporte (GONZÁLEZ; FENSTERSEIFER; 2009), para qual os professores, independentemente de serem recém-formados ou não, oriundos de cursos superiores em instituições públicas ou privadas, como é a situação da professora da EEA, não possuem a argu- 
Cultura escolar evangélica: implicações sobre os sentidos das práticas corporais Márcia Cristina Rodrigues da Silva Coffani • Cleomar Ferreira Gomes

mentação necessária que Ihes permita repensar, ampliar, incluir ou rejeitar, entre outros, o uso do esporte em seus planos de ensino. Fato que "alimenta" o imaginário social na contemporaneidade, reproduzindo no senso comum a compreensão confusa e infletida da EF apenas como prática esportiva, o que ainda parece continuar a caracterizar, justificar ou até mesmo limitar as tarefas e funções pedagógicas da EF no currículo escolar brasileiro.

Em relação aos temas transversais, há uma previsão para discussão sobre a "Ginástica de Academia", que é uma prática corporal desaconselhada aos evangélicos, com a proibição de frequentarem esse espaço social. O que nos faz questionar a sua relevância como conteúdo curricular, pois falta a esses jovens alunos essa vivência corporal.

Em entrevista com os gestores da escola fomos informados que, por razões religiosas, era proibida a prática de EF, em especial a bola era proibida nas aulas. Como também a escola não possuía um espaço esportivo ou pedagógico específico para as aulas, já que a prática era (é) proibida.

As aulas práticas de EF ocorrem nos fundos do estacionamento do Grande Templo da Igreja Evangélica Assembleia de Deus. A priori, avaliamos que talvez encontraríamos um modelo teórico de aula de EF restrita à sala de aula, com a prática de exercícios físicos compensatórios, ou antes mesmo, atividades pedagógicas relacionadas à música, ao canto, às pequenas encenações, que nos pareciam mais próximas das vivências corporais permitidas ao corpo do evangélico.

As entrevistas com os jovens alunos nos esclareceram a rotina da aula de EF no EM:

Exercício Físico. A gente faz uma corrida, depois. Depois que a gente vai fazer Rouba Bandeira ou 4 por 100. (G. - Primeiro A - EEA - M. - 15 anos). 
Cultura escolar evangélica: implicações sobre os sentidos das práticas corporais Márcia Cristina Rodrigues da Silva Coffani • Cleomar Ferreira Gomes

Desce para lá, faz o alongamento. Ai ela faz a dinâmica que ela prepara da aula dela. Ai no segundo horário, a gente já fica na sala porque o sol lá é muito quente. E também não tem lugar adequado para gente lá. Aí a gente sobe para sala. (F. - Segundo A - EEA - F. 17 anos).

Aquecimento. O professor bate em cima. O aquecimento dele é bem forte, a gente já fica bem cansado. Depois tem uma atividade que pode ser Rouba Bandeira, Pega garrafa, Leva e Traz, varia aí. (J. Terceiro A - EEA- M. - 17 anos).

As falas dos jovens alunos esclarecem que temos aulas de $\mathrm{EF}$ para os meninos com exercícios de corrida de revezamento e jogos de infância, como "Rouba Bandeira”, "Leva e Traz", "Pega Garrafa”. Já para as meninas, são aplicadas atividades de dinâmicas de grupo, ou seja, exercícios mais passivos e calmos.

Na EEA temos uma aula mista de EF, mas que na prática é dividida por gênero em função da orientação religiosa evangélica. Essa é a explicação para a presença simultânea de dois professores de EF, com e sem formação acadêmica, que se faz por necessidade de responder aos órgãos de ensino com o cumprimento de normas legislativas, que requerem a presença de professor com formação específica em cada disciplina. Por outro lado, em função das crenças religiosas, que requerem a separação dos corpos femininos e masculinos, é necessário um professor para os meninos e uma professora para as meninas, que fazem aulas no mesmo horário, mas separadas.

Evidenciamos que, na escola evangélica cristã, temos a presença da aula "mista" de EF, mas que na prática se materializa dividida em meninos com um professor e meninas com uma professora, em "espaços" diferenciados, que ocorrem ao mesmo tempo e sinalizam "lugares" distintos para educação dos corpos feminino e masculino evangélicos. O que parece estar no "fundo das aparências" (MAFFESOLI,1996) é o interdito de que os corpos de meni- 
Cultura escolar evangélica: implicações sobre os sentidos das práticas corporais Márcia Cristina Rodrigues da Silva Coffani • Cleomar Ferreira Gomes

nos e meninas se mostrem e se exponham uns aos outros, e que estabeleçam o mínimo de contato corporal possível.

A EF na escola evangélica cristã se mostra influenciada pelos valores religiosos e estéticos desse grupo social e o corpo emerge dessa realidade cultural. O corpo evangélico expressa a tradição religiosa, e é, cotidianamente, objeto de uma educação que Ihe permite incorporar os fundamentos morais e estéticos ligados à doutrina da conservação do corpo.

As aulas de EF são sempre marcadas por resistências dos jovens alunos, que parecem não atribuir sentidos pedagógicos àquilo que é feito. Diante das dificuldades físicas, materiais e pedagógicas que limitam as experiências corporais nas aulas de EF, procurou-se saber dos jovens alunos como avistam as contribuições da área para sua formação e sua vida, na escola ou "fora" dela.

Na minha opinião para saúde. Para descontrair os alunos das matérias. (G. - Primeiro A - EEA - M. - 15 anos).

No momento para mim, ela não tá servindo para nada, não. (F. Segundo A - EEA - F. - 17 anos).

E a comunicação com outras pessoas. (M. - Segundo A - EEA M. - 16 anos).

A incompreensão do papel pedagógico EF no EM pelos jovens alunos é possivelmente motivada pela falta do par: sentido e experiência, que Bondía (2002) recomenda, para pensar a educação num plano mais existencial e estético.

Os jovens alunos, ao não saberem responder para que contribui esse componente curricular, nos desafiam a refletir: de que forma a EF no EM da EEA poderia assumir um papel pedagógico 
Cultura escolar evangélica: implicações sobre os sentidos das práticas corporais Márcia Cristina Rodrigues da Silva Coffani • Cleomar Ferreira Gomes

a ser valorizado pelos jovens alunos, ao tempo, em que se respeite os cerceamentos doutrinários do evangelismo assembleiano? Uma resposta plausível é destacada (mesmo que não totalmente compreendida) pelos jovens alunos como comunicação do corpo por meio do jogo extensão do indivíduo ou do grupo (MCLUHAN, 2007).

Há um claro e problemático esvaziamento de sentido pedagógico da EF para esses jovens alunos diante da impossibilidade da vivência de outras manifestações da cultura corporal de movimento, "dentro" ou "fora" da escola; a inexistência de um espaço pedagógico adequado; a incompreensão do que "se faz" e "para que se faz" com o corpo frente à proibição da prática de EF pela doutrina religiosa evangélica cristã; a monotonia maçante e repetitiva de estafetas e pequenas corridas de revezamento nas aulas, que têm como "ponto alto" os jogos de "Rouba Bandeira", jogados, principalmente, pelos meninos.

Os jovens alunos se mostram demasiadamente desinteressados pelo que se faz e acontece na aula de EF do EM quando as atividades lúdico-corporais vivenciadas parecem alcançar um ponto de saturação, que lhes destroem suas características básicas, como jogo livre, incerto, fictício, que se presta a uma regulamentação momentânea (GOMES, 2012).

Para as alunas, as aulas de EF se aparentam como objeto de tensão quanto a impossibilidade de "usos do corpo", de explorar situações mais lúdicas e interativas. Há um nítido desconforto provocado pela vestimenta (saia), que dificulta que se sentem no chão, que se movimentem e participem de atividades de movimento mais intensas, como o jogo de "Rouba Bandeira".

A orientação do uso de saia pelas meninas, até mesmo nas aulas de EF, nos permitiu identificar o quão são limitadas as possibilidades de experiências corporais pelo corpo evangélico, para o qual, não é permitido deitar, rolar, trepar, rastejar, pendurar, entre outras formas de movimento corporal, principalmente, o feminino. Essas constatações nos levam a refletir que o discurso da "obri- 
Cultura escolar evangélica: implicações sobre os sentidos das práticas corporais Márcia Cristina Rodrigues da Silva Coffani • Cleomar Ferreira Gomes

gatoriedade" da EF no currículo escolar não Ihe garante a "legitimidade" das ações de ensino no cotidiano da escola evangélica cristã, posto que há uma negação da presença da EF com a redução das possibilidades corporais, do movimentar-se dos jovens alunos, o que pode explicar, em parte, a resistência e a desmotivação deles em relação à aula de EF no EM.

Diante desse quadro de (in)compreensão em torno da EF, buscamos indagar os jovens alunos sobre o que acham que aprendiam nessas aulas:

Melhorar o sentido de... Raciocínio. Estratégia. (G. - Primeiro A EEA- M. - 15 anos).

Estratégia de jogo. Raciocínio. Eu gosto tipo bastante, de movimento. Eu gosto bastante de alongar. Para exercitar um pouco o nosso corpo. (M. - Segundo A - EEA - M. - 16 anos).

Parceria, né. De um se entender durante o jogo, durante uma atividade. Aprende que mesmo se tiver um cara mais fraco no time, ele também é importante para o time. (J. - Terceiro A - EEA - M. - 17 anos).

As respostas dos jovens alunos sinalizam como eles reconhecem a importância do jogo nessas aulas, que nas suas falas é justificado por perspectivas utilitaristas, como oportunidade do desenvolvimento da capacidade cognitiva de raciocínio, lógica e estratégia de ação. Por outro lado, avaliamos que a EEA parece aceitar, e até mesmo recomendar, a presença do jogo nas aulas de EF por conceberem que esta prática cultural se enquadra no campo da infância, da paidia (CALLOIS,1990), da brincadeira desinteressada que se basta a si mesma, dos tempos de criança, entendendo que assim eles se mantêm a salvo, ou por parecer não constituir em um risco para debilitação moral dos jovens alunos evangélicos. 
Cultura escolar evangélica: implicações sobre os sentidos das práticas corporais Márcia Cristina Rodrigues da Silva Coffani • Cleomar Ferreira Gomes

Há que se destacar a importância e a recorrência do jogo nas aulas de EF, especialmente aquele denominado popularmente de "Rouba Bandeira". Pareceu-nos que esse é um momento de "entrega" temporal permitida do corpo ao deleite e à ociosidade. No jogo, pode-se, "[...] abandonar-se ao divertimento, à inatividade, paixão que corre o risco de tornar cada um estranho a si mesmo e a Deus. Ele pode, talvez, ser "carne" mais do que "corpo"'" (VIGARELLO, 2008, p. 304).

A vivência do jogo de regras em pequenas estafetas ou disputas, no contexto da EEA, recorrente nas aulas de EF do EM, parece ser autorizada, mas somente aos meninos, motivada pela crença de que sejam capazes de promover, tal como descreve Gomes (2012), uma educação social fundamentada pelo uso devido das regras, da aprendizagem da disciplina, e que de modo gentil escoa o fair play social no cotidiano da EEA.

\section{Considerações}

As investigações do/no/sobre o cotidiano de uma escola evangélica assembleiana descreveram a configuração da cultura escolar marcada por relações, tensões e intenções de educação do corpo dos jovens alunos, na perspectiva do evangelismo pentecostal, o que contribuiu para reflexão dos sentidos assumidos pelas práticas corporais, dentro e fora do contexto escolar.

As análises documentais, observações do cotidiano das aulas de $E F$, juntamente às "vozes" dos jovens alunos evangélicos, à luz do referencial socioantropológico que subsidiou as reflexões sobre os sentidos simbólicos das práticas corporais vivenciadas na aula de EF de uma escola evangélica cristã, sinalizam que a aula de EF e as práticas corporais são historicamente objeto de interdição e tensão em relação aos ensinamentos religiosos evangélicos imbricados à questão de gênero. $O$ imaginário social evangélico reproduz cotidianamente a imagem do corpo como sagrado e miraculoso. Esse parece ser o elemento fundamentador para restri- 
Cultura escolar evangélica: implicações sobre os sentidos das práticas corporais Márcia Cristina Rodrigues da Silva Coffani • Cleomar Ferreira Gomes

ções impostas em relação à presença e vivência das práticas corporais nas aulas de EF na escola evangélica cristã, supostamente profanas.

As práticas corporais e as expressões da cultura corporal assumem sentidos simbólicos em contingência à religiosidade cristã evangélica, com nítidas implicações pedagógicas sobre as aulas de EF no EM, que, mesmo sendo mistas, ocorrem com os corpos masculinos e femininos em separados. Há um claro ordenamento de espaço para aula que implica no isolamento dos corpos masculinos e femininos, o que contribui para a relação hierarquizada de poder, fundamentada em diferenças sexuais, e sobretudo, em conflitos em relação à presença e legitimidade da EF na escola evangélica cristã. Não se é destinado um "lugar" para as práticas corporais na educação da juventude evangélica assembleiana.

A presença da disciplina de EF no currículo escolar é marcada por conflitos junto aos jovens alunos, que revelam contradições entre o "querer-ser" e o "dever-ser", com a limitação das possibilidades de experiências com o movimento corporal, condicionadas pelo "manto" religioso; a divisão dos corpos e atividades corporais por gênero; e agravada pela falta de condições físicas e materiais para as aulas.

Há uma tocante ambiguidade no trato com o corpo na escola evangélica cristã, em função da imposição e valorização de uma cultura escolar ao corpo do "jovem aluno", marcada pela imobilidade e pelo desprezo à ludicidade e ao movimento corporal gestual, expressivo e formativo. Contudo, parece se reservar um tempo e um "lugar" para sua vivência e eclosão nas Olimpíadas Escolares ou nos jogos de "Rouba Bandeira", repetidos pelos jovens alunos (meninos) incansavelmente nas aulas de EF.

Pareceu-nos que, em meio às complexidades e resistências das normas morais religiosas, de forma sutil, a EF vem se estabelecendo como prática pedagógica, mesmo que marcada por inúmeros contrassensos sobre a sua legitimidade dentro da escola evangélica pentecostal tradicional. Para tanto, investe no caráter 
Cultura escolar evangélica: implicações sobre os sentidos das práticas corporais Márcia Cristina Rodrigues da Silva Coffani • Cleomar Ferreira Gomes

súbito, hedonista e imprevisível do jogo que é essencial à vida, especialmente dos jovens. Isso não promove o desaparecimento das proibições morais e religiosas no interior da escola, mas provoca uma redistribuição das coerções, que é mais rígida com as meninas.

O corpo é um "lugar" de inscrição simbólica que assume significações diferenciadas. Parece certo afirmar que cada cultura escolar revela um "lugar do corpo" no seu cotidiano "ordinário". Na escola evangélica cristã é o "não lugar" do corpo. O que revela a importância da investigação do que se faz do corpo e com o corpo para refletir sobre as implicações pedagógico-curriculares para EF no EM numa escola evangélica tradicional.

\section{Referências}

ALVES, M. de F. P. Religião e Sexualidade: permanências e transformações da perspectiva de jovens pentecostais de Recife/ PE - Brasil. In: Ciencias Sociales y Religión/Ciências Sociais e Religião, Porto Alegre, ano 13, n. 15, p. 83-113, Jul./Dic., 2011. BAUMAN, Z. 0 mal estar da pós-modernidade. [Tradução Mauro Gama; Cláudia M. Gama]. Rio de Janeiro: Zahar, 1998. BONDÍA, Jorge Larrosa. Notas sobre a experiência e o saber da experiência. In: Revista Brasileira de Educação, Campinas, n. 19, p. 20-28, 2002.

CALLOIS, Roger. Os jogos e os homens: a máscara e a vertigem. Lisboa, Portugal: Cotovia, 1990.

CERTEAU, M. de. A Cultura no Plural. Campinas: Papirus, 1995. CERTEAU, M. de. A invenção do cotidiano: 2. Morar, cozinhar. 9 ed. Petrópolis: Vozes, 2009.

CERTEAU, M. de. A invenção do cotidiano: 1. Artes de fazer. 18. Ed. Petrópolis: Vozes, 2012.

DURKHEIM, É. A Educação Moral. [Tradução Raquel Weiss].

Petrópolis: Rio de Janeiro, 2008. 
Cultura escolar evangélica: implicações sobre os sentidos das práticas corporais Márcia Cristina Rodrigues da Silva Coffani • Cleomar Ferreira Gomes

GOMES, Cleomar Ferreira. As brincadeiras e os jogos nos anos finais do Ensino Fundamental. In: MOREIRA, Evando Carlos (Org.). A Educação Física na rede municipal de ensino de Cuiabá: uma proposta de construção coletiva. Cuiabá: EdUFMT, 2012. p. 37-45.

GONZÁLEZ, Fernando Jaime; FENSTERSEIFER, Paulo Evaldo. Entre o "não mais" e o "ainda não": pensando saídas do não-lugar da EF Escolar I. In: Cadernos de Formação RBCE. v. 01, n. 01. 2009. Campinas: CBCE e Autores Associados, 2009.

MAFFESOLI, M. 0 Tempo das Tribos: o declínio do individualismo nas sociedades de massa. Rio de Janeiro: Forense Universitária, 1987.

MAFFESOLI, M.; ICLE; G. Pesquisa como conhecimento compartiIhado: uma entrevista com Michel Maffesoli. In: Educ. Real, Porto Alegre, v. 36, n. 2, p. 521-532, mai./ago., 2011.

MAFFESOLI, Michel. No fundo das aparências. Petrópolis: Vozes, 1996.

MAUSS, M. Sociologia e Antropologia. [Tradução Paulo Neves]. São Paulo: Cosac Naify, 2003.

MCLUHAN, Marshall. Os meios de comunicação como extensões do homem. 15. reimp. São Paulo: Cultrix, 2007.

OLIVEIRA, R. C. de. 0 trabalho do antropólogo. 2. ed. Brasília: Paralelo 15; São Paulo: Editora UNESP, 2000.

PAIS, J. M. A construção sociológica da juventude - alguns contributos. In: Análise Social, v. XXV (105-106), 1990 (1., 2º.). p. 139165.

RIGONI, A. C. C. Corpo feminino e religião: implicações para a Educação Física Escolar. IN: Revista Movimento \& Percepção, Espírito Santo do Pinhal, SP, v. 10, n. 15, jul./dez. 2009. p. 170-182. RUSSEL, B. 0 elogio ao ócio. Rio de Janeiro: Sextante, 2002. VIGARELLO, G. Exercitar-se, jogar. In: CORBIN, A.; COURTINE, Jean-Jacques; VIGARELLO, G. História do Corpo: 1 Da Renascença 
Cultura escolar evangélica: implicações sobre os sentidos das práticas corporais Márcia Cristina Rodrigues da Silva Coffani • Cleomar Ferreira Gomes

às Luzes. [Tradução: João B. Kreuch; Jaime Clasen. revisão da Tradução: Ephraim F. Alves]. Petrópolis: Vozes, 2008. p. 303-399.

WEBER, M. A ética protestante e o espírito do capitalismo. São Paulo: Pioneira, 2001.

\section{Publisher}

Universidade Federal de Goiás. Faculdade de Educação Física e Dança. Publicação no Portal de Periódicos UFG. As ideias expressadas neste artigo são de responsabilidade de seus autores, não representando, necessariamente, a opinião dos editores ou da universidade. 